\title{
NOTES
}

\section{THE DISCRIMINATION METHOD}

The discrimination method, as described by me in the "Dancing Mouse" 1 and in greater detail in my report with Watson on "Methods of Studying Vision in Anmals," " demands, in the light of results which have thus far been obtained with it, certain criticisms What I have to say at present in connection with the method is intended for the guidance of investıgators who may wish to employ it in the study of sensory discrimination or other forms of organic reaction.

The method, as described in both references, consists, essentially, in the presentation to an animal of two objects which differ with respect to one or more char acteristics on the basis of which the organism may select the one and reject the other In one form, the method consists in the presentation of two visual areas of like size, form, and brightness whose discriminable difference is color. In another form, it consists in the presentation of visual areas which differ only in brightness, in size, or in form.

The conditions of discrimination, as thus presented to an animal, are somewhat unnatural, first, because the method is, as a rule, employed in a dark-room, and, second, because the objects to be discrminated differ in fewer respects than do objects which are usually dealt with in nature Both of these possible objections to the method may be met satisfactorily by the experimenter, for the method may be employed advantageously under widely differing conditions of general illumination, and the objects to be discrimnated may be varied in complexity as seems to the experimenter desirable.

In certan recent investigations with birds and mammals, the method has yielded negrative results even after extremely long periods of training. I wish to point out that in some of these investigations the experimenters probably have wasted a considerable amount of time and energy by presenting to their animals visual objects which differ in only one respect: for example, in color, in brightness, in size, or in form.

It seems fairly certain that in our experiments we should not aum directly at our goal but, instead, begin with conditions which are rather more natural than those demanded for the accurate testing and measuring of any particular kınd of visual dircrimination by either the "brightness apparatus" or the "color apparatus." In an investigation of the perception of size, for example, it would seem safer to begin by using objects which differ in several respects. Thus the animal may more quickly be brought to attend to the proper objects and be trained to react appropriately.

Let us suppose that the initial condition of the experiment involved the use of objects which differed in brightness and form as well as in size. Then, just as

\footnotetext{
${ }^{1}$ Yerkes, Robert M. The Dancing Mouse. New York: The Macmillan Company. 1907 .

2 Yerkes, Robert M. and Watson, John B Methods of Studying Vision in Animals. The Behavior Monographs. 1911. vol. 1, no. 2.
} 
soon as the appropriate form of response appeared, the expermenter would, by eliminating the three factors one after another. ascertun the following important facts: first, which of the three characteristics of the objects the animal naturally uses, as a basis for discrimination; second, the order of importance of the three factors for the purpose of discrimination, third, the ease, accuracy, and degree of delicacy of discrimination by means of each of the factors Should the organism depend upon brightness at first, the experimenter might gradually diminish the brightness difference of the two objects until dependence upon it for discrimination became impossible. He might thus gradually bring the animal to attend to elther the size or the form of the objects, or to both Sbould it depend upon size, difference in form might immediately be elmmnated and the experimenter would then be free to proceed with his special study of the characteristics of perception of size in the organism.

In this experimental procedure there are, obviously enough, two important points: first, the use of conditions at the beginning of an investigation which are readily discriminated by the animal and which therefore permit of the acquisition of a habit quickly and without risk of discouragement; second, the directung of attention from the more readily perceived to the less readily perceived factors or characteristics of the objects through the gradual eliminution of the more important factors; third, the simplification of conditions until. finally, discrimination is made to depend upon a single sensory factor

By employing the discrimination method in some such fashion as has been suggested, the expermenter may not only obtain definite knowledge of the relative importance of different visual characteristics of objects, but he may also succeed in getting his animals to distinguish objects by means of a factor which otherwise could not be made use of. The secret of snccess is the gradual progress from the more important to the less important sensory factors of the situation Several of us have made the grave mistake of demanding of our anumals attention to objects which, although markedly unlike for us, were probably very much alike for them, or we have made the no less serious mistake of beginnıng with objects which differed in a number of important respects for the anımals, and as soon as discrimination appeared we have eliminated factors and thus abruptly increased the difficultness of discrimination. Naturally, we have experienced difficulties in getting our anmals to attend to the objects and also in preventing discouragement and refusal to attempt to discriminate

There is further the important possibility of saving time and of obtainng positive results where they otherwise would not be likely to appear by the introdurtion of still other variations in the objects

Professor Watson, in using the discrimination method for the study of color vision, has employed the device of a moving stimulus in contrast wath a stationary stimulus Thus, for example, a red stimulus area which is constant in position, size, shape, and brightness is presented beside a green stimulus area of like size, shape, and brightness. but appearing intermittently. At first, the intermittent stimulus may be interrupted at intervals of one second. This serves to attract the animal's attention to the visual areas. Gradually the rate of interruption of the one stimulus may he increased until flicker entirely disappears and the animal's attention may then continue to be directed to areas whose only difference is one of color. 
A similar device has been used by Professor Casteel in his study of visual discrimination in turtles. ${ }^{1}$ He placed white designs on pendulums and caused them to swing slowly back and forth in order that they might "attract and concentrate the attention of the animals."

Another important variation in the method is to present a single stimulus thus having only one object upon which attention is to be concentrated. The organism may be trained either to seek or to avoid the given object. Later, this object may be presented with a more or less similar object and discrimination on the basis of certain characteristics demanded.

Other variations may be introduced as seems desirable by the employment of stimuli for different senses. Visual and olfactory stimuli may be employed simultaneously, or olfactory and auditory, or visual, olfactory, and auditory. In certain cases, it may prove very advantageous to introduce stimuli which are naturally interesting to an organism even although those stimuli are not to be used otherwise than to control the attention and encourage the organism to effort.

Every experimental study of an organism emphasizes the importance of knowledge, insight, and ingenuity on the part of the investigator. He can not know too much about the habits, instincts, and environmental relations of the organism under consideration. Nor can he be too much given to distrusting and discounting the value of human experience as a guide in the study of anmal behavior.

Finally, it may not be superfuous to emphasize the importance of avoiding the overworking of animal subjects, for especially in the higher organisms it is clear that too frequent necessity for reaction to a situation, even although the reaction can be made appropriately, has a bad effect upon the organism. It is extremely important, also, to avoid discouragement on the part of the animal This may result from too frequent experimentation, too prolonged experiment: tion, or demands for discrimination under conditions which are overdifficult.

In connection with these dangers of experimentation, overfeeding is a frequent mistake on the part of experimenters. It is a good laboratory rule to supply animals with an abundance of sunlight, fresh air, to make them work for a living, and to restrict the amount of food obtaned to that necessary to keep them strong and active.

ROBERT M. YERKES

${ }^{1}$ Casteel, D. B. The discriminative ability of the painted turtle. Journal of Animal Behavior, 1911. vol 1, p. 15. 